\title{
Retention rate of hard-released translocated Egyptian tortoises Testudo kleinmanni
}

\author{
Omar Attum ${ }^{1,3, *}$, Wissam E. Farag ${ }^{2}$, Sherif M. Baha El Dinn², Bruce Kingsbury ${ }^{1}$ \\ ${ }^{1}$ Center for Reptile and Amphibian Conservation and Management, Indiana-Purdue University Fort Wayne, \\ 2101 E Coliseum Boulevard, Fort Wayne, Indiana 46805, USA \\ ${ }^{2}$ Omayed Protectorate, Egyptian Environmental Affairs Agency, Cairo-Helwan Agricultural Road, Maadi, Cairo, Egypt \\ ${ }^{3}$ Department of Biology, Indiana University Southeast, 4201 Grant Line Road, New Albany, Indiana 47150, USA
}

\begin{abstract}
We examined the suitability of using translocations as a method to create a new population of Egyptian tortoises Testudo kleinmanni in an area where the species historically occurred. We released 109 tortoises, comprising 57 males, 48 females and 4 juveniles. Dispersal from the release site influenced survival and retention rate, i.e. the proportion of individual tortoises found after the original release. The number of times a tortoise was recaptured decreased as the minimum distance at which it was found from the release site increased. In addition, live tortoises were significantly more likely to be found at shorter minimum distances from the release site than were dead tortoises. The sex ratio of pre-released tortoises tended to be different from the sex ratio of tortoises found during later surveys, with females proportionally more likely to be found than males. Prerelease mass was not a significant predictor of an individual tortoise being recaptured. Retention rates of future reintroductions may be improved by allowing tortoises to acclimatize and develop fidelity to the release site before they are translocated.
\end{abstract}

KEY WORDS: Chelonian conservation · Egypt · Reintroduction · Release site fidelity · Repatriation · Retention rate $\cdot$ Translocation $\cdot$ Testudo kleinmanni

\section{INTRODUCTION}

Reintroduction, the release of individuals of a species into an area formerly or currently occupied by that species, is a management technique for the reestablishment of rare and endangered species (Burke 1991, Fischer \& Lindenmayer 2000, Moehrenschlager \& Macdonald 2003, Tuberville et al. 2005). A translocation, the deliberate movement of wild individuals from one part of their distribution to another where the species historically occurred or is currently present, is a component of reintroductions (IUCN 1998). Reintroductions face challenges in creating viable populations because these efforts face the same problems that small populations experience. For example, a population's vulnerability to extinction is directly related to its size, with smaller populations more likely to become extinct than larger populations (O'Grady et al. 2004). Animals that have been repatriated may experience high mortality because they are not familiar with their new surroundings, spend more time moving about the landscape, cannot locate resources and are more vulnerable to predation than are residents (Kingsbury \& Attum 2009). Given the synergistic challenges associated with small populations, the release of animals into new environments, the effects of habitat degradation, anthropogenic disturbances and predation, it is easy to understand why reintroduction efforts are challenging (Kingsbury \& Attum 2009). Despite these challenges, there have been some successes (Wolf et al. 1996, Ashton \& Burke 2007, Tuberville et al. 2008). Post-release monitoring is vital to assessing the success of reintroductions. Publishing assessment results, even if the re- 
introductions are unsuccessful, is useful because such studies may suggest ways to improve future reintroduction approaches for the species of concern (Burke 1987, Dodd \& Seigel 1991, Fischer \& Lindenmayer 2000, Moehrenschlager \& Macdonald 2003, Tuberville et al. 2005, Kingsbury \& Attum 2009).

Reintroductions may have the potential to restore extirpated populations of the endangered Egyptian tortoise Testudo kleinmanni. The Egyptian tortoise is one of the smallest and most endangered tortoise species in the world, among the least studied and has the most restricted range of all tortoises in the Mediterranean Basin of North Africa and the Middle East (Baha El Din et al. 2003, Attum et al. 2007b). The range of the Egyptian tortoise extends from the western Negev in Israel, through northern Egypt and Libya (Baha El Din et al. 2003). In Egypt, most of the Mediterranean coast has been altered through urban development and large-scale agriculture, with suitable habitat remaining in only a few protected areas (Baha El Din et al. 2003). In Egypt, there has been a growth of captive assurance colonies of Egyptian tortoises, increased management of protected areas and the availability of habitat in parts of the species former range. We therefore examined the suitability of using hard-release translocations, i.e. simply releasing animals into an area without any acclimation or experience with the site, to restore populations in an area where the Egyptian tortoise formerly occurred.

\section{MATERIALS AND METHODS}

This study was conducted in Omayed Protectorate $\left(30^{\circ} 45^{\prime} \mathrm{N}, 2^{\circ} 10^{\prime} \mathrm{E}\right)$, which covers an area of approximately $700 \mathrm{~km}^{2}$ and is one of the few protected areas near the Mediterranean coast of Egypt. The release area consisted of an inland sandy and gravel plain located approximately $14 \mathrm{~km}$ from the Mediterranean coast. The vegetation community is dominated by the shrubs Thymelaea hirsute and Anabasis articulata, with vegetation cover typically ranging from 3 to $10 \%$ (Attum et al. 2007c).

The translocated tortoises, of Libyan origin, were confiscated from pet markets where they were being illegally sold in May 2005, and placed in an off-site outdoor enclosure within the Omayed Protectorate visitor center which is located approximately $8 \mathrm{~km}$ from the release site. The tortoises were fed native plants supplemented by seasonal fruit. Just before their release, the tortoises were weighed, and straight-line carapace length was measured. Tortoises were identified with unique numbers by using a numbering system that corresponded to notches filed into the marginal scutes. All tortoises appeared asympto- matic for disease, based on visual assessment; 3 tortoises were not released because of low body mass and lethargic appearance. The tortoises were all released at the same point within Omayed Protectorate on 23 September 2005.

We applied a local community approach used to conserve Egyptian tortoises in North Sinai, Egypt, by employing a member of the local Bedouin community to recapture the tortoises after their release and guard against wildlife collectors (Attum et al. 2007a, 2008). Tortoises were located in the vicinity of the release site between May and October 2007 by visually searching for and following tortoise tracks approximately every $3 \mathrm{~d}$ for a total of $10 \mathrm{~d}$ a month. In addition, the data collector often searched underneath shrubs for the presence of dead and live tortoises. The search effort involved spending 3 to $4 \mathrm{~h}$ unsystematically (no random sampling or predesignated sampling scheme) searching vegetation patches within a radius of approximately $4 \mathrm{~km}$ of the release site. Due to the nature of the sampling design, we were not able to quantify search effort.

The local person was already familiar with the vegetation patches as he regularly grazed his goats in the area. There are no data to suggest that goats physically disturb the tortoises, as tortoises and goats often graze in the same area (O. Attum unpubl. data). Pastoralists typically visit all vegetation patches within a given area and, therefore, we believe that the vegetation patches within the $4 \mathrm{~km}$ radius were equally visited. The local person occasionally visited areas up to $10 \mathrm{~km}$ away from the release site, with any observations being opportunistic. A special data sheet was created using symbols and numbers to overcome problems with literacy (Attum et al. 2007a). Data collected for every tortoise included: tortoise identification, longitude and latitude (recorded using a GPS unit), air and substrate temperature, behavior and refuge use (vegetation species and extent of cover). We used GIS software to calculate the minimum and mean straight-line distance found from the release point of all tortoise locations. The retention rate was calculated as the proportion of individual tortoises found from the original release.

We compared the sex ratio of the release group and tortoises subsequently found using chi-square analysis. We used an analysis of covariance to compare pre-release and post-capture tortoise body mass. We adjusted for body size by designating carapace length as the covariate, tortoise status (relocated versus not found) as the main factor, and mass as the response variable. We used separate linear regressions to examine the relationship between the number of recaptures for an individual tortoise and the mean and minimum distance the tortoise was found from 
the release site. The likelihood of locating dead or live tortoises based on the minimum and mean distance found from the release site was analyzed by logistic regression.

\section{RESULTS}

We released 109 tortoises comprising 57 males, 48 females and 4 juveniles. We found 21 individuals $(19.3 \%$ : males, $12.3 \%, \mathrm{n}=7$; females, $29.2 \%, \mathrm{n}=14)$ during post-release surveys approximately 2 yr later. The carcasses of 8 tortoises (6 females, 2 males) were found. The mean $( \pm \mathrm{SE})$ number of recaptures per tortoise was $11 \pm 1.7$ (range, 1 to 28 ). The mean distance and the mean minimum distance that a tortoise was captured from the release site were $982 \pm 233 \mathrm{~m}$ (range, 163 to $5060 \mathrm{~m}$ ) and $642 \pm 250 \mathrm{~m}$ (range, 31 to $5060 \mathrm{~m})$, respectively. Dead tortoise locations were only recorded once for each individual, with a mean (and minimum) location distance from the release site of $1054 \pm 170 \mathrm{~m}$ (range, 339 to $1789 \mathrm{~m}$ ).

The number of times a tortoise was recaptured decreased as the minimum distance at which the tortoise was found from the release point increased. However, this trend was not significant, due to an outlier; i.e. 1 live tortoise was located approximately $5 \mathrm{~km}$ from the release site $\left(F_{1,26}=4.18, t=-2.05, \mathrm{r}^{2}=0.14, \mathrm{p}=\right.$ 0.051 ) and later returned to the release site. The relationship between the number of recaptures and the minimum distance located from the release site was significant once the outlier was removed $\left(F_{1,25}=5.54\right.$, $t=-2.35, \mathrm{p}=0.027$ ).

A logistic regression correctly predicted $77.8 \%$ of live and dead tortoise occurrence $\left(\chi^{2}=9.16, \mathrm{df}=1, \mathrm{p}=\right.$ $0.002)$, and showed that live tortoises were significantly more likely to be found at shorter minimum distances from the release site than were dead tortoises (Wald statistic $=6.32, p=0.012$ ). In many cases, tortoises that were located at a minimum distance $>900 \mathrm{~m}$ from the release site were found dead and thus only recorded once; however, a few tortoises were also found alive at this distance from the release point (Fig. 1). There was no significant relationship between the mean distance from the release site and the number of times a tortoise was found $\left(F_{1,26}=0.74, t=-0.86\right.$, $\mathrm{p}=0.40)$ or the likelihood of finding tortoises alive $\left(\chi^{2}=\right.$ 0.035, df $=1, \mathrm{p}=0.85$ ).

Pre- and post-release sex ratios were not significantly different $\left(\chi^{2}=3.07, d f=1, p=0.08\right.$; Fig. 2 ). However, females were significantly more likely to be found than males during post-release surveys $\left(\chi^{2}=\right.$ 4.64, $\mathrm{df}=1, \mathrm{p}=0.031$; Fig. 2). The pre-release body mass, when accounting for carapace length (males: $F_{1,52}=2.45, \mathrm{p}=0.12 ;$ females: $\left.F_{1,44}=0.23, \mathrm{p}=0.64\right)$ and

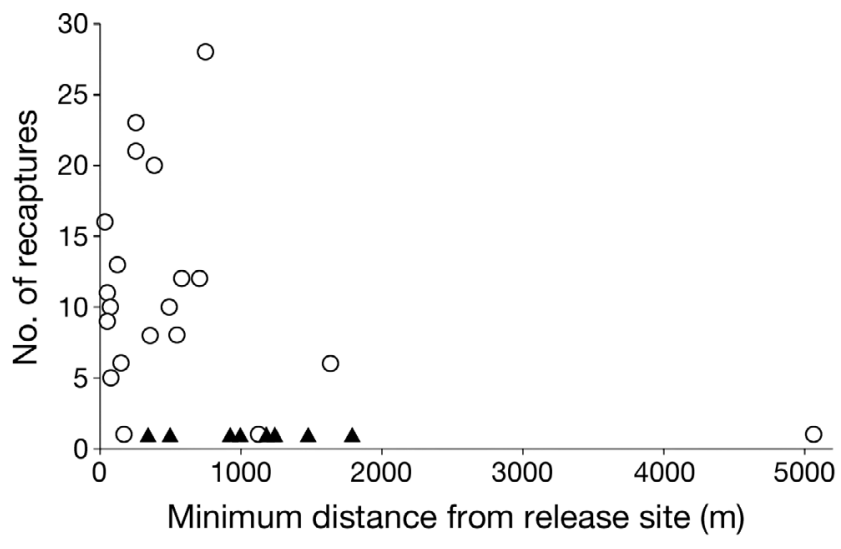

Fig. 1. Testudo kleinmanni. Relationship between the number of recaptures of individual tortoises and the minimum distance a tortoise was found from the release site. (O): Tortoises found alive; $(\boldsymbol{\Delta})$ : tortoises found dead

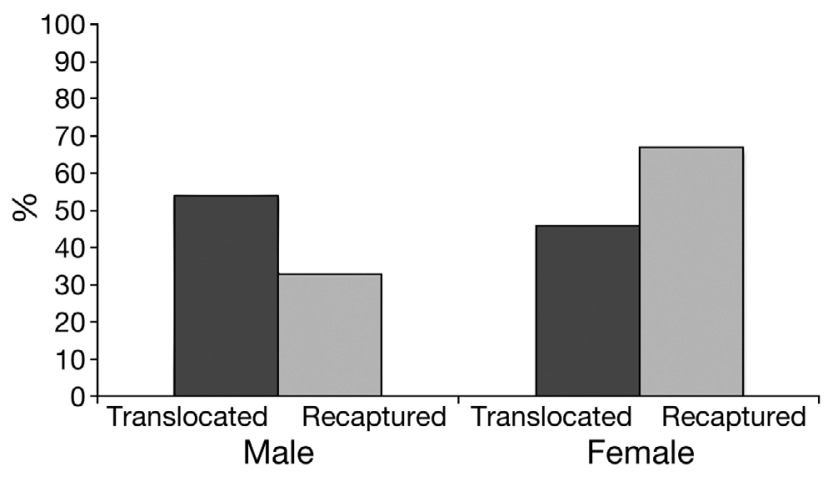

Fig. 2. Testudo kleinmanni. Comparison of the percentage of male and female tortoises in the original translocation and those recaptured in the post-release survey. Dark gray bars: sex composition of translocated tortoises $(n=105)$; light gray bars: sex composition of recaptured tortoises $(n=21)$

without accounting for carapace length (males: $F_{1,52}=$ $2.45, \mathrm{p}=0.12$; females: $F_{1,44}=0.25, \mathrm{p}=0.62$ ), was not significant between tortoises captured and those found dead. As expected, body mass was significantly related to carapace length, with longer tortoises having more mass (males: $F_{1,52}=97.44, \mathrm{p}<0.0001$; females: $F_{1,44}=$ 54.06, $\mathrm{p}<0.0001)$.

\section{DISCUSSION}

The recapture rate of reintroduced chelonians varies widely, ranging from 17 to $100 \%$, with our rates falling at the lower end of the scale (see review in Ashton \& Burke 2007). Low recapture rates of translocated animals are typically due to a combination of mortality and long-distance dispersal from the release 
site (Moehrenschlager \& Macdonald 2003, Tuberville et al. 2005, Kingsbury \& Attum 2009). A past translocation of 2 hard-released Egyptian tortoises showed that they dispersed from the release site and had activity ranges 4 to 10 times greater than activity ranges of resident tortoises from other populations (Attum et al. 2007c, 2008). Long-distance movements may be due to a number of factors, including a lack of familiarity with refugia and foraging areas, searching for familiar environmental features or exploring new surroundings (Bright \& Morris 1994, Reinert \& Rupert 1999, Moehrenschlager \& Macdonald 2003). Longdistance dispersal from the release site is undesirable because tortoises that have dispersed widely will have little or no range overlap with conspecifics (Fritts et al. 1984, Larkin et al. 2004) and could experience high mortality due to predation, anthropogenic disturbance or high energetic costs associated with greater activity (Kingsbury \& Attum 2009). The negative relationship between survival and dispersal from the release site is supported by our study, which suggests that live tortoises were more likely to be found closer to the release site than were dead tortoises (Fig. 1).

Our results emphasize the importance of considering the sex ratio of the pre-release tortoises, as the likelihood of them being relocated was partly dependent upon the sex of the tortoise. Males may have been less likely to become established because they had larger activity ranges and subsequent higher mortality than females (O. Attum unpubl. data). Thus, the sex ratio of tortoises that survive translocations may be different than the pre-release sex ratios, which could have longterm viability implications, especially in small founder populations.

A reintroduction method that could improve retention rates is the soft-release approach, whereby tortoises acclimatize and develop fidelity to the release site by being placed into a large outdoor enclosure at the release site (Lockwood et al. 2005, Tuberville et al. $2005,2008)$. Soft-releases permit the monitoring of a tortoise's behavior and health, and may give individuals time to recover from any handling stress prior to release. In addition, a series of soft-release enclosures would protect vegetation from livestock grazing and increase local biodiversity by creating a patchwork of habitat oases (Attum et al. 2006). Reintroductions using 'head-started' juveniles and subadults (i.e. neonates raised in captivity with the intent of releasing them into the wild when they reach a larger size), which have higher survival and lower dispersal than adults, used in combination with soft-release introductions may improve reintroduction success (Fritts et al. 1984, Haskell et al. 1996, Moehrenschlager \& Macdonald 2003, Larkin et al. 2004). However, the trade-off will be lower initial recruitment into the population until the younger age classes reach sexual maturity and reproduce.

The detection probability and search effort for locating tortoises in this study is unknown, and our dependence on using tracks in the sand to visually locate tortoises probably contributed to an underestimation of recapture rates. For example, the tracker was often able to determine the presence of a tortoise in a general area but unable to find the individual due to the poor visibility of the tracks. Wind, rain and the presence of livestock can remove tracks from the surface, making it difficult to follow the tortoise.

The conclusion that greater dispersal leads to greater mortality could be an artifact of search effort, as the area which has to be searched increases as linear dispersal distance increases, unless search effort per unit of ground area is constant with linear distance from the release site. While we were unable to quantify search effort accurately, tortoises found at a minimum distance of $<900 \mathrm{~m}$ from the release site were more likely to be found alive, whereas the majority of tortoises found beyond $900 \mathrm{~m}$ were found dead (Fig. 1), suggesting that our search effort was thorough. To further support our finding that the relationship between greater dispersal and mortality was not a product of search effort, the dead tortoises found beyond $900 \mathrm{~m}$ required greater search effort because the tracks had disappeared and they had to be located using the more time-consuming method of looking beneath individual shrubs. Thus, our low retention rate is due to a combination of long-distance dispersal away from the release site, tortoise mortality and our inability to recapture all individuals. For example, tracks of an Egyptian tortoise were found over $8 \mathrm{~km}$ away from the release site, but the individual was never located.

Conservation of the Egyptian tortoise should focus on protecting in situ populations through restoring habitat, preventing collection for the pet trade and testing ways to improve reintroduction retention rates. The translocated group of tortoises used for the present study should continue to be monitored, as retention rates are often low after the initial release, but stabilize in subsequent years (Ashton \& Burke 2007, Tuberville et al. 2008).

Acknowledgements. We thank Dr. M. Fouda and the Egyptian Environmental Affairs Agency for encouraging us to undertake this project. We are also grateful to the logistical support provided by M. M. Esawy. We also thank the Omayed Protectorate staff for their assistance in the field. We are indebted to E. Z. Daie for his data collection effort and keeping a watchful eye on the tortoises. We thank the anonymous reviewers and M. Thompson, whose criticisms greatly improved the manuscript. This research was made possible through support from the Center for Reptile and Amphibian Conservation and Management. 


\section{LITERATURE CITED}

Ashton KG, Burke RL (2007) Long-term retention of a relocated population of gopher tortoises. J Wildl Manag 71:783-787

Attum O, Eason P, Cobbs G, Baha El Din SM (2006) Response of a desert lizard community to habitat degradation: Do ideas about habitat specialists/generalists hold? Biol Conserv 133:52-62

Attum O, El Din MB, Baha El Din SM, Habinan S (2007a) Egyptian tortoise conservation: a community-based, field research program developed from a study on a captive population. Zoo Biol 26:397-406

Attum O, Baha El Din SM, Carranza S, Earley R, Arnold EN, Kingsbury B (2007b) An evaluation of the taxonomic validity of Testudo werneri. Amphib-Reptilia 28:393-401

Attum O, Esawy MM, Farag WE, Gad AE, Baha El Din SM, Kingsbury B (2007c) Returning them back to the wild: movement patterns of repatriated Egyptian tortoises, Testudo kleinmanni Lortet, 1883 (Sauropsida: Testudinidae). Zool Middle East 41:35-40

Attum O, Rabea B, Osman S, Habinan S, Baha El Din SM, Kingsbury B (2008) Conserving and studying tortoises: a local community visual-tracking or radio-tracking approach? J Arid Environ 72:671-676

Baha El Din SM, Attum O, Baha El Din M (2003) Status of Testudo kleinmanni and T. werneri in Egypt. Chelonian Conserv Biol 4:648-655

Bright PW, Morris PA (1994) Animal translocation for conservation - performance of dormice in relation to release methods, origin and season. J Appl Ecol 31:699-708

Burke RL (1991) Relocations, repatriations, and translocations of amphibians and reptiles: taking a broader view. Herpetologica 47:350-357

Dodd CK, Seigel RA (1991) Relocation, repatriation, and translocation of amphibians and reptiles: Are they conservation strategies that work? Herpetologica 47:336-350

Fischer J, Lindenmayer DB (2000) An assessment of the published results of animal relocations. Biol Conserv 96:1-11

Editorial responsibility: Mike Thompson,

Sydney, New South Wales, Australia
Fritts SH, Paul WJ, Mech LD (1984) Movements of translocated wolves in Minnesota. J Wildl Manag 48:709-721

- Haskell A, Graham TE, Griffin CR, Hestbeck JB (1996) Size related survival of headstarted redbelly turtles (Pseudemys rubriventris) in Massachusetts. J Herpetol 30:524-527

IUCN (International Union for Conservation of Nature) (1998) Guidelines for re-introductions. The IUCN/Species Survival Commission Re-introduction Specialist Group, IUCN, Cambridge

Kingsbury BA, Attum O (2009) Conservation strategies: captive rearing, translocation and repatriation. In: Mullin SJ, Seigel RA (eds) Snakes: ecology and conservation. Cornell University Press, Ithaca, NY, p 201-220

Larkin JL, Cox JJ, Wichrowski MW, Dzialak MR, Maehr DS (2004) Influences on release-site fidelity of translocated elk. Restor Ecol 12:97-105

Lockwood MA, Griffin CR, Morrow ME, Randel CJ, Silvy NJ (2005) Survival, movements, and reproduction of released captive-reared Attwater's prairie-chicken. J Wildl Manag 69:1251-1258

- Moehrenschlager A, Macdonald DW (2003) Movement and survival parameters of translocated and resident swift foxes Vulpes velox. Anim Conserv 6:199-206

O'Grady JJ, Reed DH, Brook BW, Frankham R (2004) What are the best correlates of predicted extinction risk? Biol Conserv 118:513-520

Reinert HK, Rupert RR (1999) Impacts of translocation on behavior and survival of timber rattlesnakes, Crotalus horridus. J Herpetol 33:45-61

Tuberville TD, Clark EE, Buhlmann KA, Gibbons JW (2005) Translocation as a conservation tool: site fidelity and movement of repatriated gopher tortoises (Gopherus polyphemus). Anim Conserv 8:349-358

> Tuberville TD, Norton TM, Todd BD, Spratt JS (2008) Longterm apparent survival of translocated gopher tortoises: a comparison of newly released and previously established animals. Biol Conserv 141:2690-2697

Wolf CM, Griffith B, Reed C, Temple SA (1996) Avian and mammalian translocations: update and reanalysis of 1987 survey data. Conserv Biol 10:1142-1154

Submitted: October 1, 2009; Accepted: February 15, 2010

Proofs received from author(s): May 12, 2010 